\title{
Distributed Power Electronics: An Enabler for the Future Grid
}

\author{
Deepak Divan and Prasad Kandula
}

\begin{abstract}
Rapidly decreasing prices for renewable energy, increasing industrialization and electrification of the global economy, and a world-wide focus on reducing carbon emissions, is causing a reexamination of the power system of the future. A reliance on centralized planning and control, scheduled and dispatched generation, and unidirectional power flows, allowed the design of a robust and scalable power system, that did not require dynamic controls infused into the grid. As a result, the existing grid, the most complex machine built by man, has been the driver of sustained global economic growth for well over a century. Increasing levels of variable and non-dispatchable renewable energy resources mixed into the grid, bidirectional power flows resulting from a dramatic increase in the number of prosumers ('producer + consumer'), are adding complexity, volatility and economic inefficiency to grid operations, making grid control with conventional centralized technologies very challenging. This paper looks at the role that distributed power electronics could play in the grid of the future, allowing a costeffective approach to grid control that can help achieve global objectives of operating with high renewable penetration.
\end{abstract}

Index Terms-Power electronics, dynamic control, power flow control, dynamic VAR control.

\section{INTRODUCTION}

$\mathrm{T}$ HE electricity infrastructure has powered the global economy over the last 100 years. A primary objective has been to provide universal and affordable energy for all, an objective that has guided the architecture and design of the power system. Early efforts at distributed, even local DC generation, were quickly replaced by centralized AC generation and transmission/distribution networks that spanned entire continents. The economics of generation from coal based thermal plants and large hydroelectric plants were tough to beat at small local scale. Further, the ability to transmit power over hundreds of miles at elevated voltages allowed the aggregation of loads such that the generation plants could be larger and more economical. Load diversity also allowed the actual thermal rating of generation and power delivery assets to be significantly lower than the total peak load connected to the grid. Similar capacity reductions are seen for power delivery assets.

The growth of the power system occurred in an era when slow electro-mechanical controls were the only option. Large

Manuscript received December 10, 2016.

The authors are with Center for Distributed Energy, Georgia Institute of Technology, Atlanta, GA, USA. (e-mail: ddivan@gatech.edu).

Digital Object Identifier 10.24295/CPSSTPEA.2016.00006 generators in vast interconnected systems had to operate with millisecond precision, balancing generation and load instantly, while maintaining voltage across geographi-cally dispersed networks. This needed inherently stable control mechanisms that would ensure that the system operated reliably and met its performance objectives. This was achieved with an array of tools including generator frequency-voltage droop profiles, slack busses, $(\mathrm{N}-\mathrm{X})$ re-dundancy in assets, meshed transmission systems, and a balancing process that included day ahead markets, locational margin pricing, as well as load-shedding as a last-ditch mechanism. With the basic system operating stably and predictably, efforts moved to overlay complex system optimization control on the power system such that availability and reliability could be further improved, and cost could be reduced. This approach has resulted in a centralized command and control structure with dispatchable generation, unassailable rights that customers have to access as much power whenever they want it, and to handle afforda-bility for poorer customers by moving to a flat pricing structure for all residential customers, and many industrial/commercial customers as well.

While this strategy has delivered sustained economic growth globally over 100 years, it has also led to a bloated electricity infrastructure, high greenhouse gas emissions [1], climate change and an inflexible system that is not sustainable. The power infrastructure is poised for dramatic change with rapid growth in non-schedulable renewable resources [2], and an increased focus on improving economic, operational and energy efficiency while reducing technical and non-technical losses. Perhaps the most profound change is the continuing year over year exponential decrease in solar PV prices [3]. With levelized cost of energy (LCOE) for PV solar farms approaching $\$ 0.03 / \mathrm{kWHr}$ in some new bids and US\$0.60/watt for PV panels, it is clear that solar is affordable and is at grid parity for a large part of the world [4]. Wind energy has followed a similar steep decrease in prices, and is seeing broad adoption globally. These successes have led to ambitious targets for renewable energy on the grid, with targeted penetration levels of greater than $50 \%$ on the power system [5]. The challenges of integrating high levels of renewable energy onto the grid cannot be underestimated - power electronics will play an increasing role in achieving this objective.

\section{HVDC AND FACTS - First NeEd For Power ELECTRONICS}

The ability to transfer AC power over increasing distances 
was limited by the inductive impedance of overhead transmission lines, requiring ever higher voltages (now approaching 1 million volts). For underground or undersea cables, it was the capacitance of the cable that limited the distance over which power could be transferred. It was recognized early on that DC power could be transferred over longer distances for both over-ground transmission lines and for underground cables. In the 1950's, the first high voltage DC (HVDC) link was built in Sweden and transferred 20 MW at $100 \mathrm{kV}$ using thyratron devices [6]. Growth of this technology required the development of the silicon thyristor by GE in the late 1950s, resulting in widespread deployment of HVDC links. This technology, the first use of power electronics on the grid, allowed delivery of gigawatts of bulk power over thousands of miles, connecting resource rich hydropower areas with large urban centers that needed the energy. Thyristor based HVDC links were very customized, required large investments in the converter stations, transformers, and the build of the line itself (not including permitting, right of way and other non-technical issues). Further, HVDC lines operated with poor and variable power factor and high harmonic levels, requiring the development of techniques to mitigate these issues [7].

The second major issue is dynamic control on the grid, the need for which has been understood for a while. Unlike traditional control systems where the variable 'analog' control is located near the source of the disturbance, in existing power systems the only 'analog' control is the AGC control on the generator - as far from loads and location of disturbances as possible. It is a testament to the ingenuity of past generations of power engineers that they made this 'backwards' control strategy work, and actually work well. As the system grew increasingly vast and loaded, there was a need to provide VAR support, not just at the generator end, but nearer the load. Synchronous condensers, often using retired generators, provided voltage support using VAR injection. Switched capacitor banks were also used to provide support when needed. However, synchronous condensers were not always available where needed, and switched capacitors were slow and had limited life. With the advent of the thyristor, a better solution was static VAR compensators (SVC), using fixed capacitor banks along with thyristor controlled reactors. For almost three decades,
SVC's rated at 50-100 MVAR provided dynamic VARs to stabilize the voltages, to improve system stability and to increase the penetration of variable wind energy on the grid. The SVC was the first of different types of flexible AC transmission systems (FACTS), devices that provided dynamic control, mostly at the transmission grid level.

As gate turn-off devices, such as IGBT's, became available, a new type of FACTS device based on voltage source converter (VSC) technology became the new gold standard. STATCOMs that could provide leading and lagging VAR support offered enhanced dynamic performance without issues related to harmonics, albeit at higher cost [8]. The concept of the unified power flow controller (UPFC) was proposed, and several were built to demonstrate voltage/ power-flow control and VAR injection capability at the transmission level [9]. While such large FACTS devices have been commercially available for decades, deployment has been limited due to cost, complexity, large footprint and high mean time to repair. Further, as wide scale deployment of renewable resources has occurred, it has become clear that dynamic control is needed at a more distributed level, and with control philosophies and cost points that are very different from existing centralized FACTS solutions.

\section{Need for Distributed Dynamic Control}

Moving from centralized control and dispatched generation to higher levels of renewable energy penetration, cause impacts that cannot easily be managed under the old paradigm. There are several distinct issues - grid integration of bulk wind and PV generation in remote areas connected to the transmission grid, dynamic balancing of instantaneous generation and load imbalances (including spatial and temporal balancing), and integration of distributed solar located at the edge of the grid. Several major challenges have been identified in all cases. The most obvious issue is the variability and lack of dispatchability of renewable resources. This leads to price volatility, ramp rates that are difficult to manage with conventional thermal generation resources, as shown in Fig. 1, and grid congestion that can lead to severe curtailment of renewable resources [10].

Issues such as time varying LMPs are all caused by dynamic balancing issues, even as the ISO operates its

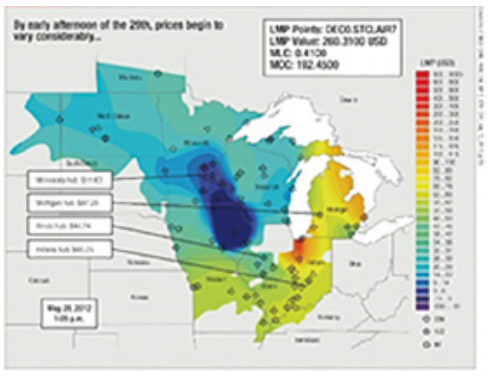

(a)

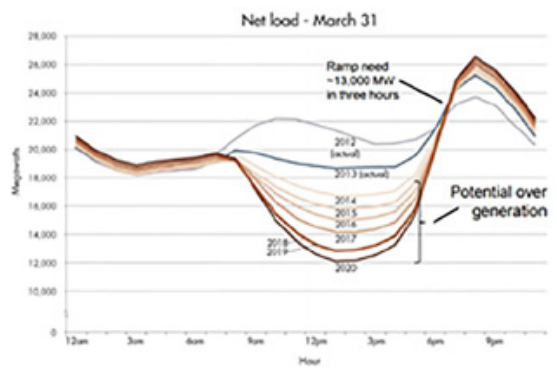

(b)

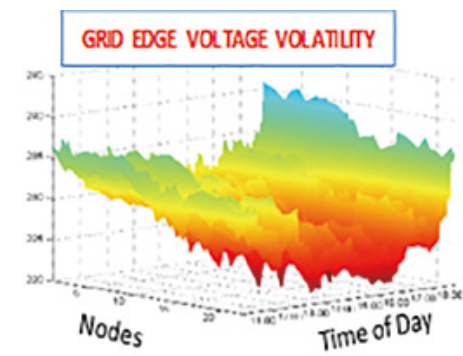

(c)

Fig. 1. Impact of high renewable penetration, a) Midwest Independent System Operator Locational Margin Pricing maps showing temporal and spatial variability from $-\$ 11 / \mathrm{MWHr}$ to $+\$ 500 / \mathrm{MWHr}$; b) California thermal ramp rates in excess of $13,000 \mathrm{MW} / 3$ hours needed to counter solar impact; c) voltage volatility on distribution feeder limits PV hosting capacity of distribution feeders [10]. 
various wholesale market mechanisms. The ability to direct power from low-cost areas to high-cost areas over the existing network would help improve system efficacy. With the existing meshed sub-transmission and transmission networks, directing power flows is challenging, often resulting in heavy congestion of corridors, severe curtailment of renewable resources, and an unnecessary increase in the use of non-optimal resources that results in higher cost and higher emissions [11].
Mainly two control levers exist to achieve dynamic control on the grid - Voltage control and VAR injection. These levers can be used to achieve significant objectives including power flow control in meshed grids, demand control, and integration of high levels of renewable energy into the grid.

Fig. 2 shows various power electronic technologies that can provide the above mentioned two control levers at different locations on the grid. The next three sections provide a brief description of some of the technologies.

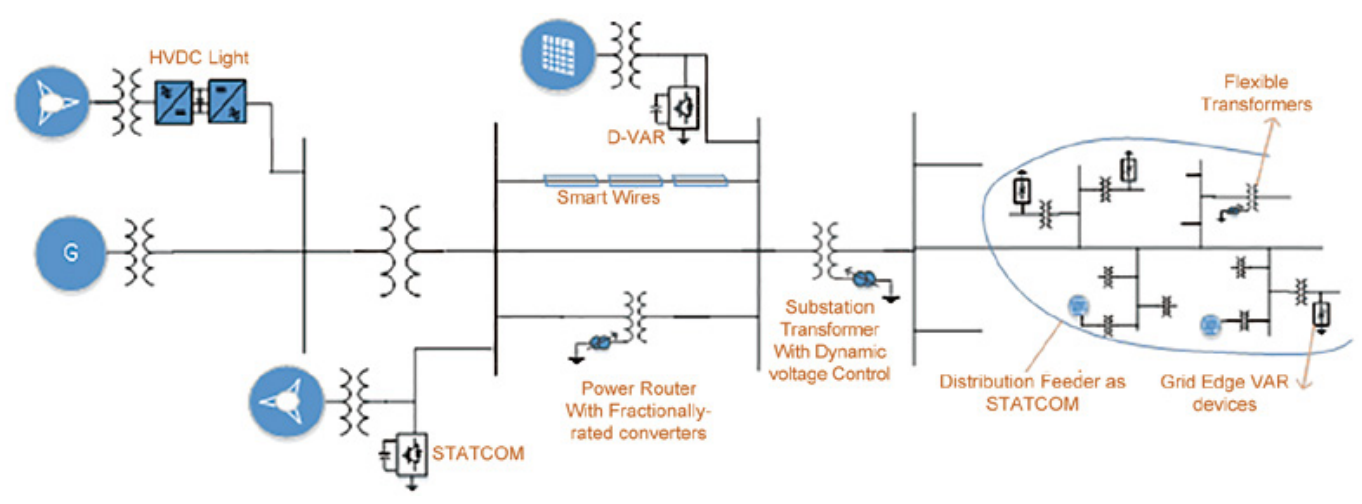

Fig. 2. Various power electronic technologies that can provide Volt/VAR control and phase angle control to realize power flow control, voltage support and other dynamic control functions at different locations on the grid.

\section{Dynamic Power Flow Contro -Transmission SYSTEMS}

\section{A. HVDC Light}

HVDC light, successor to conventional HVDC technology, is based on voltage source converter technology using IGBTs and other gate turn-off devices [12]. Compared to conventional HVDC, HVDC light technology has superior reactive power control capability. It can provide independent control of active and reactive powers increasing the transfer capacity of the AC network surrounding the terminal. Such features enable applications in areas such as:

- Connecting wind farms to power grids

- Underground power links

- Providing shore power supplies to islands and offshore oil \& gas platforms

- Connecting asynchronous grids

- City center infeed

A variant of HVDC light using back-to-back (BTB) converter ( no DC cables) can be used to achieve power flow control, which can aid in integrating variable renewable resources. An example is the 220 MW HVDC BTB system at Oklaunion, Texas, USA [13]. The schematic of HVDC light with back-to-back converter is shown in Fig. 3. It consists of two transformers and two converters each rated at 1.0 $\mathrm{pu}$ of the throughput power. A HVDC BTB system can inject $1.0 \mathrm{pu}$ voltage in series with the line.

HVDC Light technology now reaches 1,800 MW and $\pm 500 \mathrm{kV}$. But in most applications, $1.0 \mathrm{pu}$ power flow control can be achieved with $0.05-0.15$ pu voltage injection mainly because of the low line impedance (5-15\%) [14]. Hence, HVDC BTB may be an overkill for simple power flow control applications, but is a viable option when needed to integrate asynchronous systems, provide low-frequency power oscillation damping, improve stability margins etc.

\section{B. Multi-Point HVDC Light}

An extension of HVDC light is the HVDC multi-terminal system, which can be used to form regional and interregional HVDC systems [15]. Regional multi-terminal HVDC system (Fig. 4) can reduce the number of converters required to connect multiple sources to the grid. Interregional HVDC multi-terminal systems (Fig. 5) can form the basis for HVDC grids. HVDC grids present an alternative to conventional HVAC systems, which are becoming increasingly difficult to build because of environmental, right-of-way issues [16].

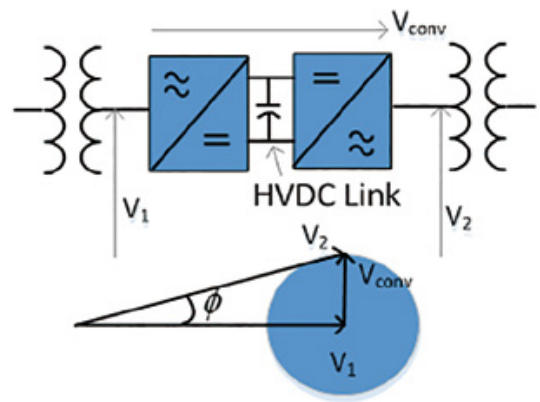

Fig. 3. Schematic of HVDC Light implementation with back-to-back converter. 


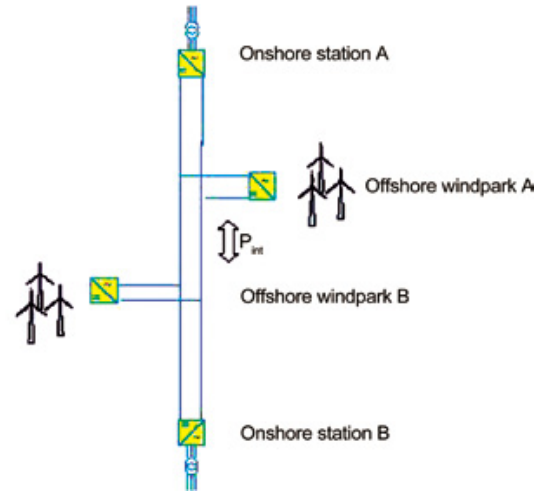

Fig. 4. Regional multi-terminal HVDC grid [15].

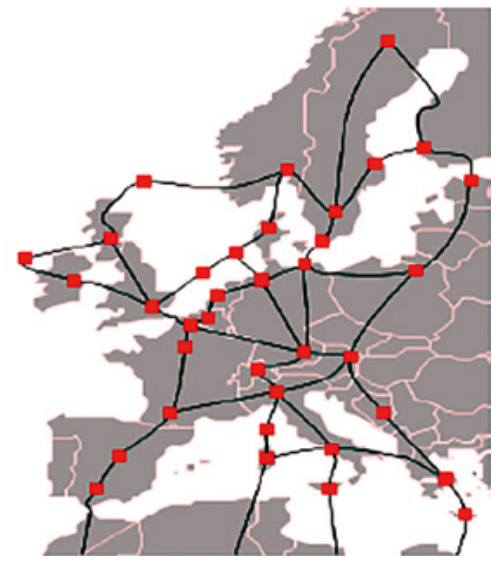

Fig. 5. Interregional multi-terminal HVDC grid [15].

\section{Power Flow Control Using Fractionally-Rated Converters}

As stated above, HVDC BTB technology may be too expensive for simple power flow control applications within AC networks. FACTS devices such as unified power flow controller (UPFC) [17] based on fractionally-rated converter topologies have been proposed for dynamic power flow control. The UPFC concept uses two fractionally-rated, transformer-coupled inverters to achieve independent control of the real and reactive power flow on the transmission line. Several UPFCs have been built to demonstrate the concept, including a 300 MVA device in New York, but widespread deployment has not occurred. The cost and complexity of the solution, including the ability of the series transformer to withstand short circuit faults, are perhaps key challenges. Further, even infrequent downtime due to failures and a long mean time to repair can have significant impact on UPFC availability/reliability. Based on many conversations with utility engineers in the US, it appears that the complexity and cost associated with large centralized FACTS devices, and the dependence of the utility on vendors for critical maintenance and operations, has made the business case very challenging. As a result, even though FACTS solutions, such as the UPFC, have been commercially available for $20+$ years, very few have been deployed. Another approach is required to achieve these very real and tangible benefits.

\section{Power Flow Control Using Distributed 'Fail-Normal' Devices}

Based on utility feedback, Divan [18] proposed the concept of distributed power flow control devices, where several devices could be used to achieve the desired control range. Each device would operate over a narrower range, and would be used to augment existing/conventional utility assets by overlaying the dynamic control capability on what is otherwise a passive asset. The power converters used would be small-rated and modular, and would be designed with 'fail-normal' capability, such that the asset would operate conventionally (i.e. without dynamic control) if the converter were to fail, or under short-circuit system faults. This also provided the utility with assurance that the desired control capability could be maintained even when individual control devices failed. This set of basic principles provides the basis for a new class of distributed utility solutions that better meet utility operational requirements at modest cost.

Implementations of 'fail-normal' power router technologies based on fractionally-rated converter and magnetics include the controllable network transformer (CNT), which consists of a load tap changing transformer augmented by a direct AC converter [19], and a power router that consists of a transformer augmented with a fractionally-rated backto-back converter (FR-BTB) [20], Implementation of CNT and FR-BTB are shown in Fig. 6. Since the converter is connected across the taps, the converters have to handle only fractionally voltage and hence, the fractional rating. These technologies affect control over real and reactive power by series injecting voltage with different phase angle and amplitude, respectively.
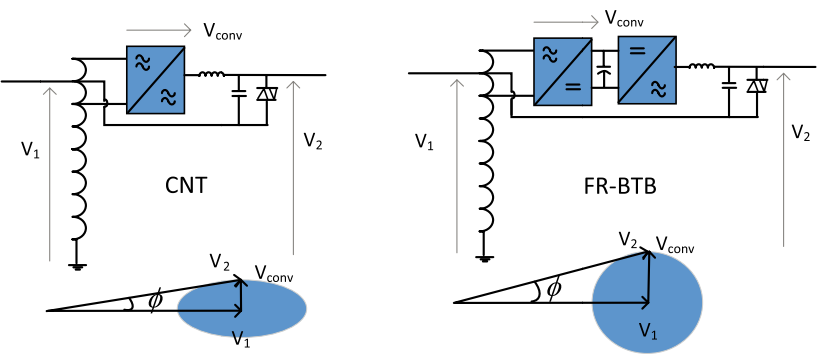

Fig. 6. Schematic of controllable network transformer (CNT) and power router based on fractionally-rated BTB converter (FR-BTB). The 'failnormal' thyristor switch can be seen in both schematics.

The CNT however is optimized for applications that require more reactive power flow control than real power flow control such as in loop-flow management in a meshed grid. The FR-BTB topology uses standard three level converters in a back-to-back configuration to achieve symmetrical control over both real and reactive power. On the other hand, the FR-BTB utilizes bulk-energy storage in the form of electrolytic capacitors, with size and life limitations. Another approach called the compact dynamic phase angle regulator (CD-PAR) [21] addresses implementation of a power flow control device optimized for control over real power without using any bulk energy storage. 
Both the CNT and FR-BTB topologies have been demonstrated at the $13 \mathrm{kV} / 1 \mathrm{MW}$ level, demonstrating the ability to control power flows with small rated transformers and converters, as well as the concept of fail-normal operation. However, both topologies require the electronics to be floating at the line voltage. Implementations of floating converters have challenges such as protecting sensitive electronics against corona damage, and ensuring adequate isolation exists between the floating and grounded parts and between components floating at two different phases [21]. Further, like any piece of utility gear, the BIL rating needs to be well coordinated with the surrounding protective gear on the system. For example, any equipment operating in a $13 \mathrm{kV}$ system typically require a BIL rating ranging from 90 to $120 \mathrm{kV}$. A design must be able to incorporate sensitive electronics within a product that is able to sustain this level of voltage impulse without any damage.

To avoid challenges of a floating system, a modified approach of CD-PAR, with changes to the design such that the electronics are much more closely coupled to the ground potential is proposed in [22]. As shown in Fig. 7, the "grounded" CD-PAR employs a fully-rated LTClike transformer augmented with fractionally-rated direct AC converters [23], [24]. With a small modification of the transformer configuration, and with the addition of power converters connected across the neutral-side taps, a device that provides dynamic phase angle control can be obtained.

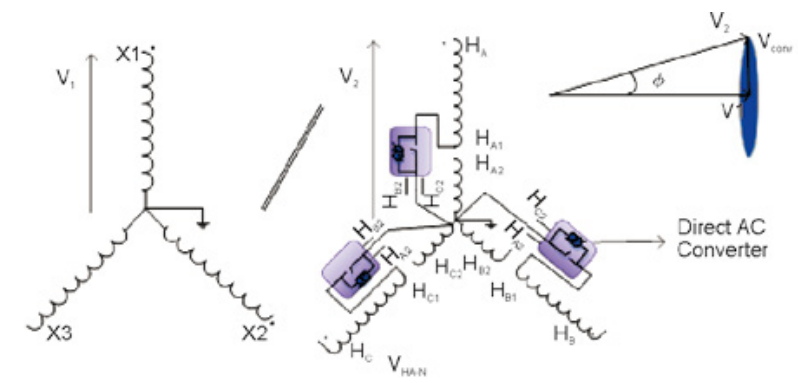

Fig. 7. Grounded compact dynamic phase angle regulator schematic [24].

A $13 \mathrm{kV}, 1$ MVA 3-phase grounded CDPAR has been built and tested in the field on a $13 \mathrm{kV}$ distribution feeder [25]. The device was connected across two distribution feeders and was shown that the power flow between the substations can be dynamically controlled by varying the orthogonal series voltage injection. The advantages of fractionally-rated converter based solution was demonstrated by achieving 600 $\mathrm{kVA}$ of power flow control at $13 \mathrm{kV}$ with a converter rated for $35 \mathrm{kVA}$ and rated to handle $500 \mathrm{~V}$.

In contrast with CDPAR with floating converter, the grounded CDPAR implementation requires a full-rated transformer, which makes it more cost effective for applications that also require voltage step up/down and/ or galvanic isolation functionality. For simple power flow control applications, the grounded CDPAR provides a practically implementable solution in short term. Once the issues associated with floating electronics are addressed and demonstrated at reasonably higher voltages, CDPAR with floating converter nay prove to be even more economical.

\section{E. Distributed Series Impedance (DSI)}

Distributed Series Impedance (DSI) module wires is an impedance control device belonging to distributed FACTS (D-FACTS) family [18]. DSI converts a transmission line to a smart asset providing ability to control power flows in meshed transmission systems. The schematic of DSI, shown in Fig. 8, consists of a single turn transformer with control circuitry on the secondary. The control circuitry, consisting mainly of a fast switching switch, acts to add either inductance $\left(\mathrm{X}_{\mathrm{M}}+\mathrm{X}_{\mathrm{L}}\right)$ or capacitance $\left(\mathrm{X}_{\mathrm{C}}\right)$ to the line, thereby increasing or decreasing line impedance, respectively.

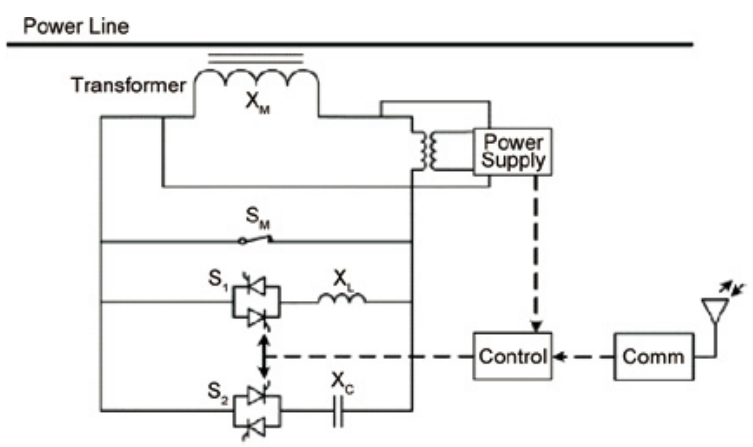

Fig. 8. Schematic of Distributed Series Impedance (DSI).

As the name suggests, DSI is a distributed solution, with multiple modules clamped directly over the line conductor as shown in Fig. 9(a). With a large number of modules operating together, it is possible to have a significant impact on the overall power flow in the line. If $\mathrm{N}$ device are used in series along a power line, one can realize $2 \mathrm{~N}$ discrete values as shown in Fig. 9(b). In $\mathrm{N}$ is large, say 100, a resolution of $0.5 \%$ can be achieved, approximating a linearly varying line impedance.

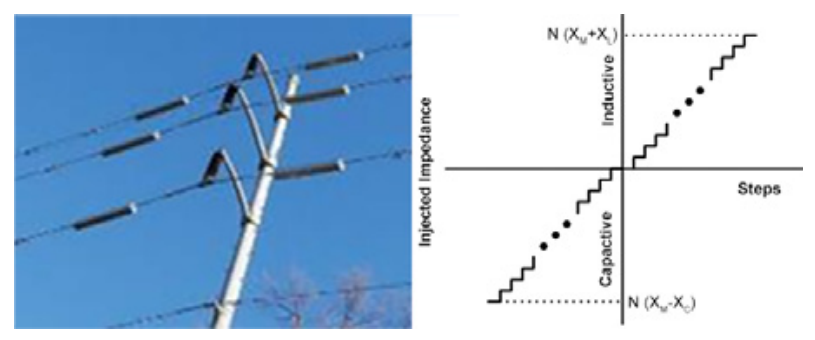

Fig. 9. (a) Distributed modules of Smart Wires [26]. (b) Control range of $\mathrm{N}$ DSI modules.

DSI is an inverter-less solution that can be installed on an existing transmission line without requiring a breakin-the-wire. The simplicity allows the DSI module to withstand short circuit current, meet basic insulation level (BIL) requirements, handle high E-fields, eliminate corona discharge, and operate through punishing freeze/ thaw and heat/cool cycles. A variant of DSI, calvled 
Powerline Guardian ${ }^{\mathrm{TM}}$ by Smart Wires Inc, is commercially available, with multiple modules operating on high voltage transmission lines [26].

\section{Dynamic Volt/Var CONTROL-Transmission}

Intermittent sources of energy such as wind and solar can impact the quality and reliability of the electrical network. Dynamic shunt VAR support devices can detect and instantly compensate for voltage fluctuations, mitigate impacts of flicker, and correct power factor, protecting wind farms, solar parks and the electrical grid. Some of the prominent shunt VAR support devices are presented here.

\section{A. STATCOM}

Static Synchronous Compensator (STATCOM) is a second generation FACTS device, which is based on gate turn-off devices [27]. STATCOM works on the principle of generating reactive power by circulating currents in the phases through a switching converter. It consists of a Voltage Source Converter (VSC) connected in shunt with the line through a relatively small reactance $(0.1-0.15$ p.u.). On the input side of the converter is a DC capacitor, essential to maintain the equality of the instantaneous input and output powers. The converter is usually an array of semiconductor switches with forced turnoff capability (GTO thyristors or IGBTs).

STATCOM can either generate or absorb reactive power, and can respond quickly to damp any big disturbance on the power system, which is possible because the reactive power generated by STATCOM is not voltage dependent. The first STATCOM in U.S. was a +/- 100 MVAR installation at Sullivan substation of Tennessee Valley Authority (TVA), in 1995 , for regulating the $161 \mathrm{kV}$ bus voltage [8]. Other prominent U.S. installations are as follows: +/- 86 MVAR, $115 \mathrm{kV}$ STATCOM at Essex substation, in 2001 [28] ; +/100 MVAR STACOM at Talega, in 2002 ; the +/- 95 MVAR STATCOM at Holly substation in 2004.

\section{B. D-VAR}

Dynamic VARs (D-VARs) are modular STATCOMs offered by American Semiconductor Inc. [29]. The modular approach offers a cost-effective, scalable system that allows utilities to install properly sized systems in the most effective power grid locations, staging the installation as desired, and quickly augmenting capability as demands increase. D-VAR solutions are available up to $46 \mathrm{kV}$ and 100s of MVARs. The necessity of dynamic voltage support in future grid is supported by the number of recent D-VAR commercial installations at wind power plants, providing voltage regulation that will respond dynamically to varying load conditions [30].

\section{Dynamic Volt/Var control-Distribution}

Utilities are observing greater voltage volatility at the grid. Though a number so studies have shown that voltage volatility can occur because of high residential photo-voltaic (PV) [31]-[34], filed studies have shown that volatility can exist on systems even without significant PV [35]. Voltage volatility at grid-edge cannot be managed using traditional electromechanically switched centralized command and control solutions, which all have slow response and a limited number of operations [36]. Control at grid edge is required to meet the new challenges that utilities are facing as a result of grid modernization initiatives such as energy conservation, peak demand management, grid integration of distributed PV, grid integration of distributed PV, and improved service reliability and quality [35], [37].

Power electronics-based solution implemented on the secondary side of the distribution transformer for voltage regulation are commercially available [38], [39]. Some of the solutions are presented here.

\section{A. Thyristor-Assisted Tap Changer}

The voltage fluctuations caused by PV are much more frequent and a standard electro-mechanical tap-changer (ex. OLTC) may not withstand the resulting wear and tear Thyristor-assisted tap changers have been proposed to improve reliability, useful life and tolerance against voltage spikes and thermal endurance under fault currents.

The schematic of typical thyristor-assisted tap changer is shown in Fig. 10 [40]. The structure is similar to a standard mechanical tap-changer except that the taps are now selected using thyristors. Also the voltage is injected using an additional auxiliary transformer, which aids in providing isolation between the electronic circuit and the HV winding.

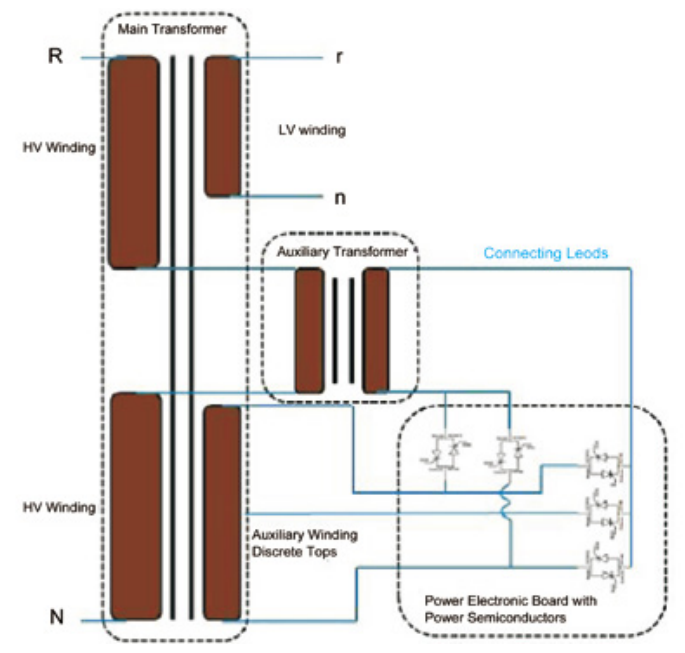

Fig. 10. Schematic of thyristor-assisted tap changer [40].

\section{B. Flexible Field-Upgradable Transformers}

The major drivers for voltage control on distribution systems are the cost and reliability. The standard distribution transformer is pretty inexpensive ( $\$ 1200$ for 1 -phase 50 kVA unit) and is very robust. To be commercially viable, 
addition of a new controller should not impact either the cost or the reliability. One of the methods to achieve this is the flexible transformers consisting of a standard distribution transformer with a slight modification to add taps at the low voltage end, as shown in Fig. 11 [41]. A cold plate is also integrated with the transformer housing, which will be used for mounting the electronic module. This mechanism allows passive cooling design, significantly extending the device life time by removing fans. The electronic module can include a power converter that provides voltage and/or VAR control, and can do so at very low cost.

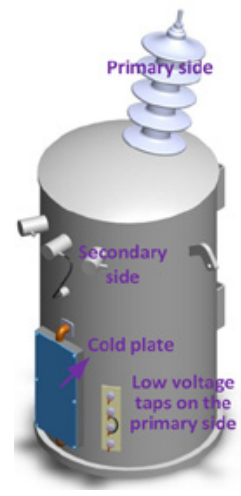

(a)

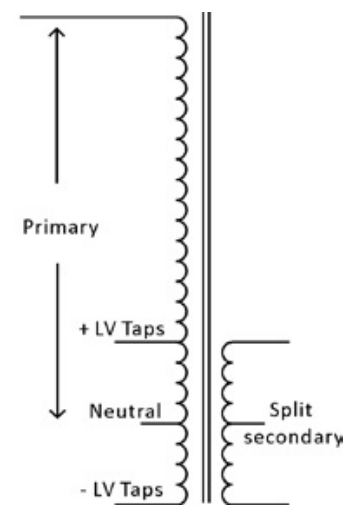

(b)
Fig. 11. Flexible transformer: a) CAD model; and b) winding schematic [41].

When the electronic module fails, the transformer retains basic passive transformer functionality. The converter is only fractionally-rated ( $5 \mathrm{kVA}$ for $50 \mathrm{kVA}$ unit), avoids direct fault current and is located near the ground potential to avoid BIL issues [42]. Hence, the converter contributes very little additional weight and loss for the system while achieving wide-range dynamic voltage control.

\section{Grid Edge Volt-Var Devices}

Use of reactive power support available from solar converters is suggested to address voltage volatility [31]. But this approach has issues. Utilities cannot control where the PV systems are deployed or mandate VAR support from customer owned devices. Further, multiple inverters connected to the grid acting autonomously can result in interactions, causing 'hunting' and compromising stability. This concern has been recognized and is being addressed by groups such as the Smart Inverter Working Group in California [43].

Another approach is through the use of fast-acting distributed power electronics devices at the grid edge to achieve volt-var control [44]. The edge-of-network grid optimization $\left(\mathrm{ENGO}^{\mathrm{TM}}\right)$ devices are basically low-cost fast acting switched capacitor solution. They operate autonomously on the secondary side of the distribution system and eliminate the nasty variations that are seen due to poor power factor loads and other grid disturbances. A swarm of these gridedge VVC controllers can act in unison to tame the grid into a well-behaved system and unlock a simple grid-edge VVC scheme to achieve $5-7 \%$ of energy and demand control, increase system efficiency by $10 \%$ and dramatically increase PV hosting capacity of distribution feeders.

An image of the installed ENGO device and the feeder voltage control achieved is shown in Fig. 12. More than 3000 ENGO devices managed by GEMS have been deployed at over 15 utilities around the world and have been shown to achieve voltage support, peak demand, energy savings, loss minimization, increased PV hosting [45], and the ability to use the distribution feeder itself as a STATCOM [46].
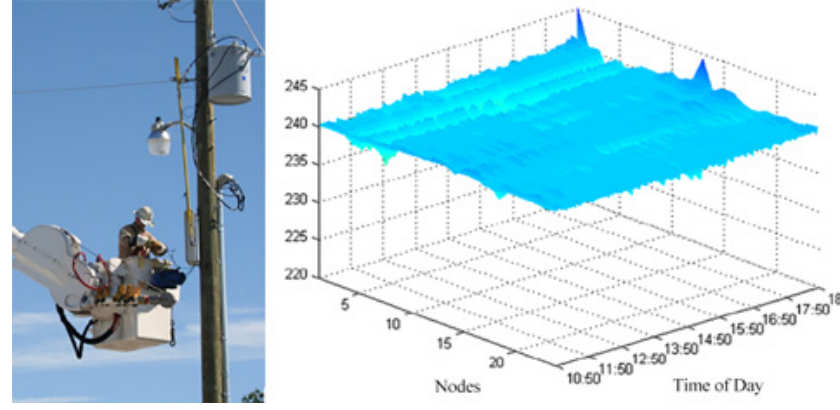

Fig. 12. a) Installed grid edge VVC devices (courtesy Varentec), b) feeder voltage profile after correction. (see Fig. 1(c) for profile before correction)

\section{CONCLUSIONS}

This paper has looked at the role that power electronics has played in grid control, and has presented a view of how distributed power electronics devices may shape the grid of the future. Many of the problems in the future grid are distributed in nature, due to increasing use of distributed generation, and the evolution of smart autonomous devices. The existing centralized control paradigm is unable to manage the increased complexity and volatility. The possibility of interactions between intelligent autonomous devices is real and must be addressed.

New solutions have been demonstrated and are being deployed in the field to attest to these new capabilities. New concepts are necessary for distributed power electronics to meet the reliability and ruggedness demanded in grid applications. This includes 'fail-normal' operation, an overlay and augment strategy, and the use of fractionally rated converters and passive components. The era of distributed control is just beginning, and the future grid cannot be controlled using passive techniques, the way it has been for the past 100 years.

\section{REFERENCES}

[1] EnergyInformationAuthority-USA, "Electric Power Annual," 2016.

[2] EnergyInformationAuthority-USA, "Short Tern Energy Outlook," 2016.

[3] CleanTechnica. 13 Charts On Solar Panel Cost \& Growth Trends [Online]. Available: https://cleantechnica.com/2014/09/04/solarpanel-cost-trends-10-charts/

[4] S. Mahapatra. Dubai Gets Record-Low Bid Of 2.99 $\mathrm{k} / \mathrm{kWh}$ For 800 MW Solar PV Project. [Online]. Available: https://cleantechnica. com/2016/05/02/lowest-solar-price-dubai-800-mw-solar-project 
[5] Green TechMedia, "California Passes a Bill Targeting 50\% Renewables by 2030, , ed.

[6] ABB. The evolution of HVDC. [Online]. Available: http://www.abb. us/cawp/db0003db002698/3f1519fa63f99cc8c12572dd002c4f51. aspx

[7] R. L. Sellick and M. Åkerberg, "Comparison of HVDC Light (VSC) and HVDC Classic (LCC) site aspects, for a 500MW 400kV HVDC transmission scheme," in 10th IET International Conference on $A C$ and DC Power Transmission (ACDC 2012), 2012, pp. 1-6.

[8] C. Schauder, M. Gernhardt, E. Stacey, T. Lemak, L. Gyugyi, T. W. Cease, et al., "Development of a \&plusmn;100 MVAr static condenser for voltage control of transmission systems," IEEE Transactions on Power Delivery, vol. 10, pp. 1486-1496, 1995.

[9] L. Gyugyi, "A unified flow control concept for flexible AC transmission systems," in International Conference on $A C$ and $D C$ Power Transmission, 1991, pp. 19-26.

[10] J. C. Lori Bird, and Xi Wang. Wind and Solar Energy Curtailment: Experience and Practices in the United States. [Online]. Available: http://www.nrel.gov/docs/fy14osti/60983.pdf

[11] DoE-USA, "National Transmission Grid Study," May 2002.

[12] ABB. Special report 60 Years of HVDC. [Online]. Available: https:// library.e.abb.com/public/fcf44b87ad51488d87b3de433abb7273/ HVDC\%20special\%20report\%20-\%20FINAL_2.pdf

[13] ABB. $220 \mathrm{MW}, 345 \mathrm{kV} D C, H V D C$ BTB Installation at Oklaunion, Texas, USA. [Online]. Available: http://new.abb.com/systems/hvdc/ references/oklaunion

[14] G. H. Narain and G. Laszlo, "FACTS Concept and General System Considerations," in Understanding FACTS:Concepts and Technology of Flexible AC Transmission Systems, ed: Wiley-IEEE Press, 2000, pp. 1-35.

[15] A. Bjorn Jacobson. Development sin Multiterminal HVDC. [Online]. Available: http://www.ieee.ca/epec11/admin/04-0800-hvdc_plenary_ jacobson.pdf

[16] "HVDC Grid Feasibility Study," presented at the Working Group, B4.52, CIGRE, April, 2013.

[17] L. Gyugyi, "Unified power-flow control concept for flexible AC transmission systems," Generation, Transmission and Distribution, IEE Proceedings $C$, vol. 139, pp. 323-331, 1992.

[18] D. Divan and H. Johal, "Distributed FACTS-2014; A New Concept for Realizing Grid Power Flow Control," IEEE Transactions on Power Electronics, vol. 22, pp. 2253-2260, 2007.

[19] D. Das and D. Divan, "Power flow control in networks using controllable network transformers," in Energy Conversion Congress and Exposition, 2009. ECCE 2009. IEEE, 2009, pp. 2224-2231.

[20] R. P. Kandula, A. Iyer, R. Moghe, J. E. Hernandez, and D. Divan, "Power Router for Meshed Systems Based on a Fractionally Rated Back-to-Back Converter," Power Electronics, IEEE Transactions on, vol. 29, pp. 5172-5180, 2014.

[21] A. Prasai, R. P. Kandula, R. Moghe, T. Heidel, C. Schauder, and D. Divan, "Compact dynamic phase angle regulator for power flow control," in 2015 IEEE Energy Conversion Congress and Exposition (ECCE), 2015, pp. 4985-4992.

[22] Anish Prasai, R P Kandula, Rohit Moghe, Timothy Heidel, Colin Schauder, and Deepak Divan, "Compact Dynamic Phase Angle Regulator For Power Flow Control," in Unpublished.

[23] D. M. Divan and A. Prasai, "Dynamic power flow controllers," PCT/ US2014/035210, 2014.

[24] R. P. Kandula, A. Prasai, H. Chen, R. Mayor, F. Lambert, T. Heidel, et al., "Design considerations and experimental results for a 12.47kV 3-phase 1 MVA power router," in 2015 IEEE Energy Conversion Congress and Exposition (ECCE), 2015, pp. 5000-5007.

[25] P. Kandula, H. Chen, A. Prasai, T. Heidel, C. Schauder, F. lambert, et al., "Field Test Results for a 3-Phase $12.47 \mathrm{kV} 1$ MVA Power Router," in ECCE, 2016.

[26] SmartWires. POWERLINE GUARDIAN [Online]. Available: http:// www.smartwires.com/powerline-guardian/

[27] L. Gyugyi, "Reactive power generation and control by thyristor circuits," in Power Electronics Specialists Conference, 1976 IEEE, 1976, pp. 174-184.

[28] G. Reed, J. Paserba, T. Croasdaile, M. Takeda, Y. Hamasaki, T. Aritsuka, et al., "The VELCO STATCOM based transmission system project," in 2001 IEEE Power Engineering Society Winter Meeting. Conference Proceedings (Cat. No.01CH37194), 2001, pp. 1109-1114 vol.3.

[29] AmericanSuperconductor. Dynamic Volt-Amp Reactive (D-VAR $\left.{ }^{\circledR}\right)$ Compensation Solution. [Online]. Available: http://www.amsc.com/ documents/d-var-data-sheet/

[30] AmericanSuperconductor. AMSC Announces \$10 Million in D-VAR ${ }^{\circledR}$ System Orders in North America. [Online]. Available: http://ir.amsc.com/releasedetail.cfm?ReleaseID $=959107$

[31] Y. Liu, J. Bebic, B. Kroposki, J. d. Bedout, and W. Ren, "Distribution System Voltage Performance Analysis for High-Penetration PV," in Energy 2030 Conference, 2008. ENERGY 2008. IEEE, 2008, pp. 1-8.

[32] M J E Alam, K M Muttaqi, D Sutanto, L. Elder, and A. Baitch, "Performance Analysis of Distribution Networks under High Penetration of Solar PV," presented at the CIGRE 21, rue d'Artois, F-75008 PARIS, 2012.

[33] S. J. Lewis, "Analysis and management of the impacts of a high penetration of photovoltaic systems in an electricity distribution network," in Innovative Smart Grid Technologies Asia (ISGT), 2011 IEEE PES, 2011, pp. 1-7.

[34] J. W. Smith, R. Dugan, and W. Sunderman, "Distribution modeling and analysis of high penetration PV," in 2011 IEEE Power and Energy Society General Meeting, 2011, pp. 1-7.

[35] D. Divan, R. Moghe, and A. Prasai, "Power Electronics at the Grid Edge : The key to unlocking value from the smart grid," IEEE Power Electronics Magazine, vol. 1, pp. 16-22, 2014.

[36] P. Wood, V. Bapat, and R. P. Putkovich, "Study of improved load tap changing for transformers and phase-angle regulators," Elect. Power Res. Inst, Palo Alto, CA, USA1988.

[37] D. Divan, H. Chen, and A. Prasai, "Systems and methods for switchcontrolled var sources coupled to a power grid," Jun. 2013.

[38] Varentec. Edge of Network Grid Optimization (ENGO). [Online]. Available: http://varentec.com/products/engo-v10/

[39] Gridcosystems. Low Voltage Pole-mounted 50kVA In-line Power Regulator. [Online]. Available: http://gridcosystems.com/products/ lv-ipr-50-pole/

[40] D. Rivas, E. Betancourt, and O. Mendez. Distribution Transformer With Automatic Maintenance Free Electronic Tap Changer Featuring Robust Low Current Zero Switching. [Online]. Available: http:// www.ieee-pes.org/presentations/td2014/td2014p-000581.pdf

[41] Hao Chen, Rajendra Prasad Kandula, Anish Prasai, Joe Schatz, and D. Divan, "Flexible Transformers for Distribution Grid Control," presented at the ECCE, 2016.

[42] R.P. Kandula, H. Chen, A. Prasai, and D. Divan, "Field upgradeable transformer: a fractionally-rated voltage regulator for the distribution system," presented at the IEEE Energy Conversion Congress and Exposition, 2016

[43] California-Energy-Commission. Rule 21 Smart Inverter Working Group Technical Reference Materials. [Online]. Available: http:// www.energy.ca.gov/electricity analysis/rule21/

[44] R. Moghe, D. Tholomier, D. Divan, J. Schatz, and D. Lewis, "Grid Edge Control: A new approach for volt-var optimization," in 2016 IEEE/PES Transmission and Distribution Conference and Exposition (T\&D), 2016, pp. 1-5.

[45] R. Moghe, D. Tholomier, and D. Divan, "Distribution grid edge control: Field demonstrations," in 2016 IEEE Power and Energy Society General Meeting (PESGM), 2016, pp. 1-5.

[46] R. Moghe, D. Divan, D. Lewis, and J. Schatz, "Turning distribution feeders into STATCOMs," IEEE Transactions on Industry Applications, vol. PP, pp. 1-1, 2016. 


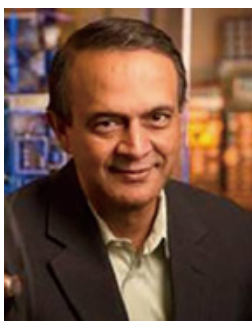

Deepak Divan received the B.Tech. degree from the Indian Institute of Technology, Kanpur, India, in 1975, and the M.Sc. and Ph.D. degrees from the University of Calgary, Calgary, AB, Canada, in 1979 and 1983, respectively. He has been a Professor in electric engineering with the University of Wisconsin-Madison. From 2011 to 2015, he was the President and CTO of Varentec, San Jose, CA, USA, a company focused on grid edge control that is funded by clean-tech venture capital firm Khosla Ventures and investor Bill Gates, where he currently serves as the Chief Scientist and Founder. He is the John E. Pippin Chair Professor and the Director at the Center for Distributed Energy, Georgia Institute of Technology, Atlanta, GA, USA. He is also the Scientific Founder of two additional companies-Innovolt, based in Atlanta, which makes next-generation power protection and asset management devices and where he serves on the Board, and Soft-Switching Technologies Corporation, where he served as the CEO and developed a range of devices to help manufacturing facilities ride through power disturbances. He has 40 years of academic and industrial experience, 65 issued and pending patents, and over 400 refereed publications. Dr. Divan is a Member of the U.S. National
Academy of Engineering. He is the first person to receive the IEEE William E. Newell Power Electronics Award, and is a President of the IEEE Power Electronics Society.

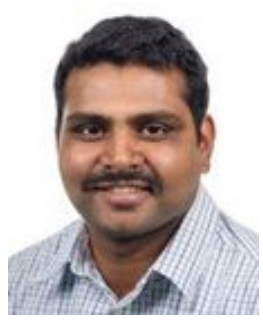

Rajendra Prasad Kandula received his B.E in Electrical Eng. from NIT, Nagpur, India in 2002 and M.E from IISC, Bangalore, India in 2004. He worked for 3 years in BHEL R\&D Hyderabad as design engineer in the area of industrial drives and $\mathrm{PV}$ applications. He received his $\mathrm{PhD}$ in electrical eng. from Georgia Institute of Technology, Atlanta, USA in 2013. He worked at Varentec, Santa Clara as Principal engr. mainly working in the area of development of power routers for meshed transmission systems. He is currently working as Chief Engineer at Center for Distributed Energy, Georgia Tech, Atlanta . His main research interests are applications of power electronics for utility applications such as power routers, hybrid filters etc. 